\title{
Changes in Tyrosine Hydroxylase mRNA Expression in the Rat Locus Coeruleus Following Acute or Chronic Treatment with Valproic Acid
}

Scott Alan Sands, Ph.D., Victoria Guerra, and David Andrew Morilak, Ph.D.

Valproate has proven effective in treating bipolar disorder. Though some biochemical effects of valproate are rapid, mood-stabilizing effects can take weeks, suggesting that regulatory changes in gene expression in brain neurotransmitter systems may be involved. Given a presumed role for norepinephrine (NE) in bipolar disorder, as well as the actions of mood-stabilizing drugs, we examined changes in $m R N A$ expression for tyrosine hydroxylase (TH), the NE transporter (NET) and $\alpha_{2 A}$ autoreceptor in the rat locus coeruleus after valproate treatment. TH mRNA increased slightly (16\%) following acute treatment, and more so after chronic valproate treatment (26\%), while neither NET nor $\alpha_{2 A} m R N A$ expression changed. Further, chronic valproate treatment attenuated the elevation in TH $m R N A$ expression induced in the LC in response to acute restraint stress. Both acute and chronic valproate treatment attenuated restraint stressinduced elevations in plasma ACTH secretion. These observations suggest that the therapeutic effects of valproate may involve regulatory alterations in $\mathrm{TH}$ message expression in the brain, and attenuation of stress-reactivity of the central noradrenergic system and the hypothalamicpituitary-adrenal axis. [Neuropsychopharmacology 22:27-35, 2000] (C) 1999 American College of Neuropsychopharmacology. Published by Elsevier Science Inc.
KEY WORDS: Valproic acid; Locus coeruleus; In situ hybridization; Tyrosine hydroxylase; Norepinephrine; Antimanic

It has long been hypothesized that dysregulation of central norepinephrine (NE) neuronal systems might be involved in the expression if not the development of major affective disorders, including depression and mania (Schatzberg and Schildkraut 1995; Schildkraut

From the Department of Pharmacology, University of Texas Health Science Center at San Antonio, 7703 Floyd Curl Dr., San Antonio, Texas, USA.

Address correspondence to: David A. Morilak, Department of Pharmacology University of Texas Health Science Center at San Antonio, 7703 Floyd Curl Drive, San Antonio, TX 78284-7764. Tel.: 210-567-4174. Fax: 210-567-4303. E-mail: morilak@uthscsa.edu

Received April 12, 1999; revised June 9, 1999; accepted June 16, 1999.
1965). The noradrenergic neurons of the locus coeruleus (LC), situated in the dorsal pons, project widely throughout the central nervous system, representing the source of noradrenergic terminals innervating many forebrain and limbic regions such as the amygdala, hippocampus, hypothalamus and neocortex (Moore and Bloom 1979). As such, these neurons are ideally poised to exert global modulatory or state-related changes in brain activity. Central NE, and the LC in particular, is hypothesized to play an important role in attention, arousal and behavioral activation (Aston-Jones et al. 1991; Charney et al. 1990; Foote et al. 1983; Puumala et al. 1997; Siegel and Rogawski 1988), all of which may be severely disrupted in mood disorders, especially those involving a manic component such as bipolar affective disorder. Thus, the noradrenergic neurons of the LC may represent potential targets for mood stabilizing drug treat- 
ment, and are likely to reflect at least some of the regulatory mechanisms responsible for their therapeutic effects.

Effective therapeutic agents have been developed for the treatment of bipolar disorder. Lithium has been the primary treatment for bipolar disorder, although its side effects are many and often severe, and its mechanism of action is still relatively unknown (Bowden et al. 1994). Recently, certain classes of antiepileptic agents, including valproic acid (VPA), have proven to be as effective as lithium in the treatment of mania and bipolar disorder, and possess a more benign adverse effect profile and a broader therapeutic margin of safety (Bowden et al. 1994; Loscher 1993). The mechanism of action of VPA for the treatment of affective disorders is largely unknown. By contrast, the mechanisms by which it acts as an antiepileptic have been more extensively examined. The biochemical effects of VPA occur rapidly, and include the inhibition of GABA transaminase (and thus inhibition of GABA catabolism) and a decrease in sodium channel activity (Van den Berg et al. 1993). Similarly, the antiepileptic effects of VPA are observed quickly, whereas the antimanic effects of VPA require a much longer course of treatment, as long as 2-3 weeks (Bowden et al. 1994). Because of this, the mechanisms of action underlying the antimanic action of VPA may be distinct from those underlying its antiepileptic effects. Thus, it would be informative to investigate the induction of long-term regulatory, reactive, or compensatory alterations that may occur in the brain after administration of mood stabilizing drugs such as VPA.

The long time course over which adaptations occur with mood stabilizers suggests that changes in gene expression for components of brain neurotransmitter systems important in regulation of affect may be involved. Past results suggest that drugs used in the treatment of affective disorders can indeed induce regulatory or compensatory alterations in gene expression for various components of the noradrenergic neurotransmitter system. For example, administration of tricyclic antidepressants such as desipramine decreases tyrosine hydroxylase $(\mathrm{TH})$ mRNA expression in the LC (Brady et al. 1991; Morilak et al. 1998; Nestler et al. 1990). Thus, in the first experiment of the present study, we examined potential changes in TH gene expression in the LC following acute and chronic administration of VPA. To test for the specificity of any VPA-induced changes in TH mRNA expression, we also measured mRNA encoding two other components of the noradrenergic system expressed in the LC, the norepinephrine transporter (NET) and $\alpha_{2 \mathrm{~A}}$ adrenergic autoreceptor. In the second experiment, the effects of acute or chronic VPA treatment on acute stress-reactivity of $\mathrm{TH}$ gene expression in the LC noradrenergic neurons were examined. In addition, because of the presumed role of NE in activation of the hypothalamic-pituitary-adrenal stress axis, changes in plasma ACTH levels following acute stress in VPA-treated rats were also measured. Portions of this work have been presented in abstract form (Morilak et al. 1998).

\section{MATERIALS AND METHODS}

\section{Experiment 1: Effect of Valproate on Basal LC Gene Expression}

70 adult male Sprague-Dawley rats (250-300 g; Harlan, Indianapolis, IN) were group housed, 3 per cage, for a minimum of 10 days prior to initiating the experiment. This experiment was conducted in three replications (the animals tested in the third replicate also served as unstressed control subjects in Experiment 2 below). Animals were maintained on a 12:12 light/dark cycle (lights on at $0700 \mathrm{~h}$ ), and allowed ad libitum access to food and water throughout. The animals were randomly assigned to one of four treatment groups. The drug treatments were vehicle (sterile distilled water) or VPA $(600 \mathrm{mg} / \mathrm{kg} /$ day) administered either acutely (2 days) or chronically (2 weeks). In pilot studies, it was found that the VPA solution gelled at the concentrations necessary to deliver the desired daily dose by osmotic minipump. Thus, because of the short half-life of VPA in rats (approximately $90 \mathrm{~min}$ ), VPA was administered s.c. 3X daily $(200 \mathrm{mg} / \mathrm{kg}$ in each injection in a concentration of $200 \mathrm{mg} / \mathrm{ml}$ sterile distilled water) at $0700 \mathrm{~h}$, $1500 \mathrm{~h}$ and $2300 \mathrm{~h}$ (Loscher et al. 1989). In a series of preliminary investigations, it was determined that this dosing regimen consistently produced plasma VPA levels, sampled $4 \mathrm{hr}$ after the last injection, of $40-50 \mu \mathrm{g} / \mathrm{ml}$, very close to the target therapeutic level of $50 \mu \mathrm{g} / \mathrm{ml}$. Control animals received equivalent volumes of vehicle on the same injection schedule. Four hours after the final injection, animals were sacrificed by rapid decapitation, the brains were removed, frozen by immersion in isopentane on dry ice, and stored at $-70{ }^{\circ} \mathrm{C}$ until use (less than one month).

\section{Experiment 2: Effect of Restraint Stress on LC Gene Expression and Plasma ACTH Levels After Valproate Treatment}

68 adult male Sprague-Dawley rats (33 of which were also used in Experiment 1) were housed and maintained as above. Drug treatment regimens were also identical to those described above. Beginning two to three hours after the final injection, half of the control and valproate-treated rats were subjected to $1 \mathrm{hr}$ restraint stress using Centrap restraint devices (Fisher Scientific). At the end of the $1 \mathrm{hr}$ restraint period, rats were then decapitated, trunk blood was collected in chilled polypropylene tubes containing EDTA $(1 \mathrm{mg} / 1 \mathrm{ml}$ 
blood collected), and the brains were processed as above.

\section{In Situ Hybridization}

Procedures for in situ hybridization were essentially the same for both experiments. Six sequential series of $20-\mu \mathrm{m}$ adjacent sections were cut through the LC on a cryostat. Sections were thaw mounted onto silanecoated glass microscope slides, two per slide. The slidemounted sections were fixed $15 \mathrm{~min}$ in $4 \%$ paraformaldehyde, dehydrated in $70 \%$ ethanol, air-dried and stored at $-70{ }^{\circ} \mathrm{C}$ until a sufficient number of brains had been cut for simultaneous processing (typically 12-16 brains per hybridization). Within each hybridization procedure, an equal number of brains from each treatment group at any time point were cut, processed and quantified together to minimize systematic variability.

Radiolabeled riboprobes were synthesized from linearized cDNA plasmids using a commercially available transcription kit (Stratagene) according to the manufacturer's directions, with the addition of $\alpha-{ }^{35} \mathrm{~S}-\mathrm{UTP}$ (New England Nuclear) to a specific activity of $2 \times 10^{9} \mathrm{cpm} /$ $\mu \mathrm{g}$. The $275 \mathrm{nt}$ TH probe was transcribed from a cDNA template obtained from Dr. Stanley Watson, University of Michigan; the $690 \mathrm{nt} \alpha_{2 \mathrm{~A}}$ probe was synthesized from a cDNA template obtained from Dr. Stephen Lanier, Harvard Medical School, and the 660 nt NET riboprobe was transcribed from a cDNA template obtained from Dr. Richard Simerly, Oregon Health Sciences University. After transcription, riboprobes were separated from free nucleotide using Sephadex spin columns.

All solutions used for prehybridization and hybridization were treated with diethyl pyrocarbonate and autoclaved or filter sterilized. At the time of hybridization, brain sections were thawed, hydrated in PBS, acetylated in $0.25 \%$ acetic anhydride $/ 0.1 \mathrm{M}$ triethanolamine, $\mathrm{pH}$ 8.0, and rinsed in 2X SSC (1X SSC is $150 \mathrm{mM}$ sodium chloride, $15 \mathrm{mM}$ sodium citrate, $\mathrm{pH}$ 7.2). Sections were then dehydrated in an ascending series of ethanol washes, delipidated in chloroform, and airdried before hybridization. Hybridization buffer consisted of $50 \mathrm{mM}$ sodium phosphate, 3X SSC, 5X Denhardt's solution, $0.1 \mathrm{mg} / \mathrm{ml}$ salmon sperm DNA, 0.1 $\mathrm{mg} / \mathrm{ml}$ yeast tRNA, $10 \mathrm{mM}$ dithiothreitol, $10 \%$ dextran sulfate, and $50 \%$ deionized formamide. Sections were hybridized under glass coverslips in $60 \mu$ l of hybridization buffer to which radiolabeled riboprobe had been added to a final concentration of $4 \times 10^{7} \mathrm{cpm} / \mathrm{ml}$ (approximately $20 \mathrm{ng} / \mathrm{ml}$ ). They were then placed on racks and incubated overnight in a sealed humidified chamber at $60^{\circ} \mathrm{C}$. Control probes synthesized from the sense strand of each template were applied to a small number of sections to verify specificity of the label.

All post-hybridization solutions contained $10 \mathrm{mM}$ $\beta$-mercaptoethanol. After hybridization, excess probe was removed by rinsing in four washes of 2 XSC, then digesting the sections with RNase A $(20 \mu \mathrm{g} / \mathrm{ml}, 30 \mathrm{~min}-$ utes at $37^{\circ} \mathrm{C}$ ). They were then taken through a series of rinses of increasing stringency: $10 \mathrm{~min}$ each in $1 \mathrm{X}, 0.5 \mathrm{X}$, and $0.2 \mathrm{X}$ SSC. The conditions for the final high-stringency wash varied depending on the probes: for the $\mathrm{TH}$ and the $\alpha_{2 \mathrm{~A}}$ probes, sections were washed for $3 \times 1 \mathrm{hr}$ in $0.1 \mathrm{X} \mathrm{SSC}, 15 \%$ formamide at $60{ }^{\circ} \mathrm{C}$. For the NET probe, sections were washed for $3 \times 1 \mathrm{hr}$ in $0.2 \mathrm{XSC}$ at $60{ }^{\circ} \mathrm{C}$. Following the high-stringency wash, sections were rinsed in 1X SSC, dehydrated and apposed, along with ${ }^{14} \mathrm{C}$-radioactive standards, to Kodak Biomax MR X-ray film for $19 \mathrm{hr}(\mathrm{TH}), 76 \mathrm{hr}\left(\alpha_{2 \mathrm{~A}}\right)$ or $19 \mathrm{hr}$ (NET).

\section{Data Analysis}

Digitized images of film autoradiograms were captured with a Sony XC-77 CCD camera coupled to a Scion LG-3 capture board in a PowerMac 7100 computer. Image signal intensity on each film was calibrated using a standard curve constructed from ${ }^{14} \mathrm{C}$-standards exposed along with the sections. Signal overlying the LC was then analyzed densitometrically using the public domain NIH-Image software package (v. 1.55, Wayne Rasband, NIH). Integrated density for each probe, expressed in standard units of $\mathrm{nCi} / \mathrm{mg}$, was measured in 4-6 LC sections per brain, corresponding to plates 5658 in the Atlas of Paxinos and Watson (Paxinos and Watson 1986). Mean integrated density was then calculated from these measurements to generate a single value for each animal. The resulting data were then analyzed by ANOVA, followed by post-hoc analyses, where appropriate, with the Newman-Keuls test. Significance of any observed differences was determined at $p<.05$.

\section{Plasma ACTH Measures}

Upon collection of the trunk blood, samples were centrifuged at $4500 \mathrm{rpm}$ for $15 \mathrm{~min}$, at which time plasma was removed, frozen, and stored at $-80^{\circ} \mathrm{C}$ until assayed. Plasma ACTH values were determined in duplicate $200 \mu \mathrm{l}$ samples by direct radioimmunoassay according to manufacturer's instructions (Nichols Institute Diagnostics, San Juan Capistrano, CA). Resulting data were analyzed by ANOVA, followed by post-hoc analyses with Newman-Keuls test. Significance of any observed differences was determined at $p<.05$.

\section{RESULTS}

Hybridization with all three riboprobes produced a specific and robust signal overlying noradrenergic neu- 
A

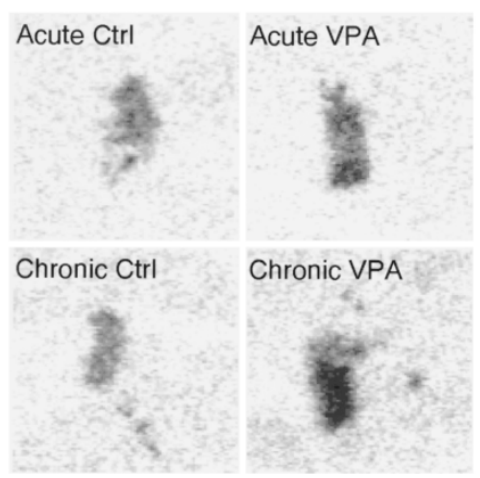

B

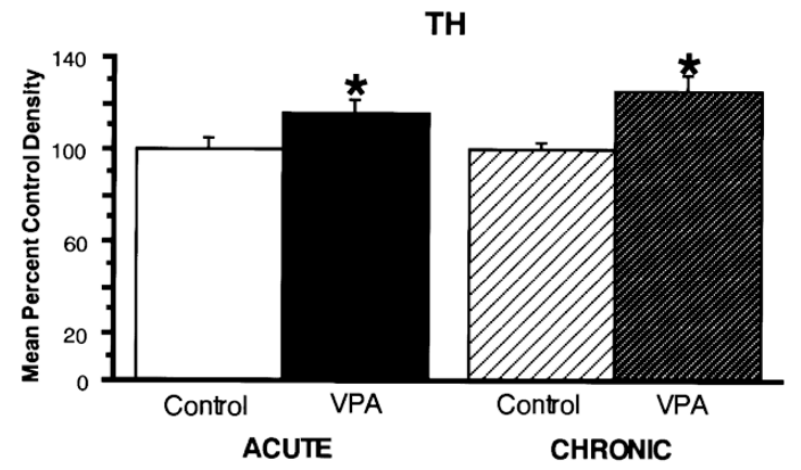

Figure 1. Effects of acute or chronic valproate (VPA) on TH mRNA expression in the locus coeruleus. (A) Representative autoradiographs of TH mRNA expression following acute vehicle control treatment $(\mathrm{n}=15)$, acute VPA treatment $(\mathrm{n}=14)$, chronic vehicle control treatment $(n=22)$, and chronic VPA treatment $(n=19)$. (B) Mean integrated density expressed as percent of vehicle control for TH mRNA expression following acute and chronic valproate treatments. *: significantly different $(p<.05)$ from respective vehicle-treated controls.

rons of the LC (Figures 1A, 2A, 3A). In no case was any signal ever observed with the sense control probes. Treatment with VPA exerted a significant effect on body weight gain during the course of the treatment. Vehicle-treated animals gained $55 \pm 3 \mathrm{~g}$ during the 2-week treatment period, while VPA-treated rats gained $26 \pm 2 \mathrm{~g}(n=20$ each, $\mathrm{t}=81.66, p<.0001)$. Even acute VPA treatment attenuated the mean increase in body weight seen during the two-day drug treatment period $(10 \pm 4$ g vs. $0 \pm 4 \mathrm{~g}, n=14$ each, $\mathrm{t}=41.26, p<.0001)$.

\section{Experiment 1: Effect of Valproate on Basal LC Gene Expression}

Treatment of rats with VPA caused a significant increase in $\mathrm{TH}$ message expression in the LC $\left(\mathrm{F}_{1,66}=\right.$
20.268, $p<.001$; Figure 1). Post-hoc comparisons further revealed that, as compared to the respective vehicle-treated control animals, TH mRNA expression was significantly elevated in both acute and chronic valproate-treated rats, to $116 \%$ and $126 \%$ of their vehicletreated controls, respectively (Figure 1). By contrast, neither acute nor chronic VPA treatment induced significant changes in NET (Figure 2) or $\alpha_{2 A}$ (Figure 3) mRNA expression in the LC.

\section{Experiment 2: Effect of Acute Restraint Stress on LC Gene Expression and Plasma ACTH Levels Following Valproate Treatment}

Unlike Experiment 1, there was not a significant elevation in $\mathrm{TH}$ mRNA expression in LC following acute
A

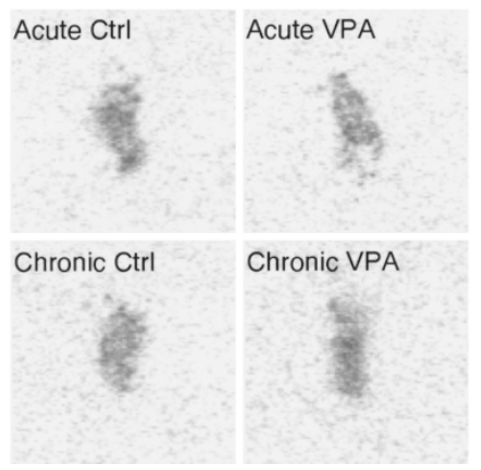

B

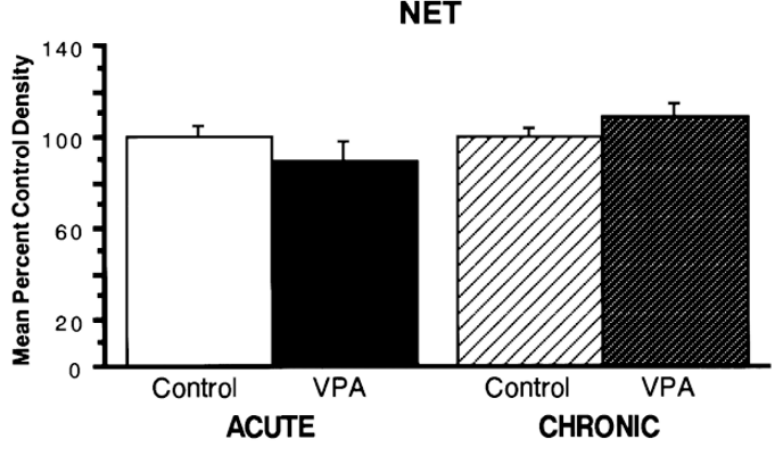

Figure 2. Effects of acute or chronic valproate (VPA) on NET mRNA expression in the locus coeruleus. (A) Representative autoradiographs of NET mRNA expression following acute vehicle control treatment $(\mathrm{n}=15)$, acute VPA treatment $(\mathrm{n}=$ 15), chronic vehicle control treatment $(\mathrm{n}=21)$, and chronic VPA treatment $(n=19)$. (B) Mean integrated density is expressed as percent of vehicle control for NET mRNA expression following acute and chronic valproate treatments. No significant differences in NET mRNA expression were observed. 
A

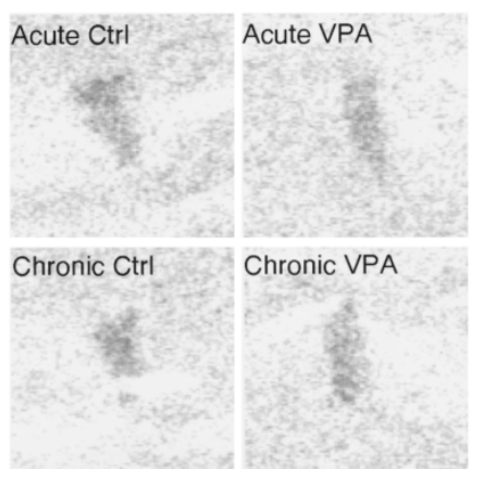

B

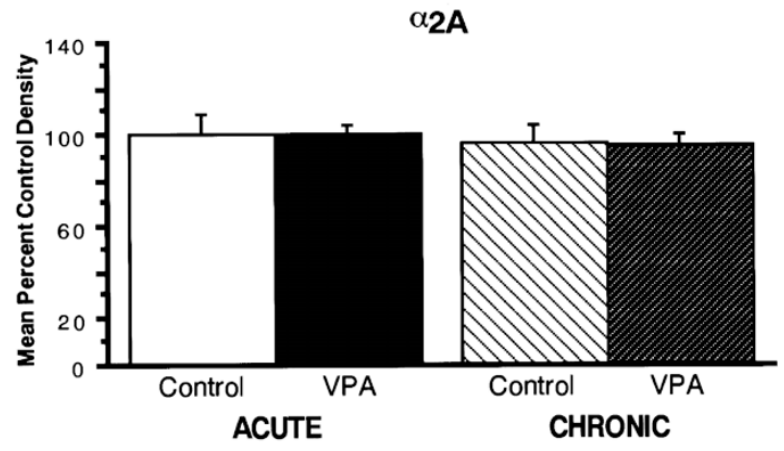

Figure 3. Effects of acute or chronic valproate (VPA) on $\alpha_{2 A}$ mRNA expression in the locus coeruleus. (A) Representative autoradiographs of $\alpha_{2 A}$ mRNA expression following acute vehicle control treatment $(n=15)$, acute VPA treatment $(n=16)$, chronic vehicle control treatment $(n=19)$, and chronic VPA treatment $(n=16)$. (B) Mean integrated density is expressed as a percent of vehicle control for $\alpha_{2 \mathrm{~A}}$ mRNA expression following acute and chronic valproate treatments. No significant differences in $\alpha_{2 \mathrm{~A}}$ mRNA expression were observed.

A

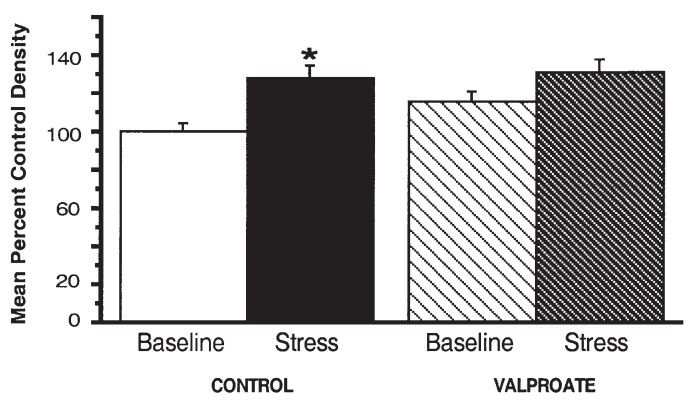

B

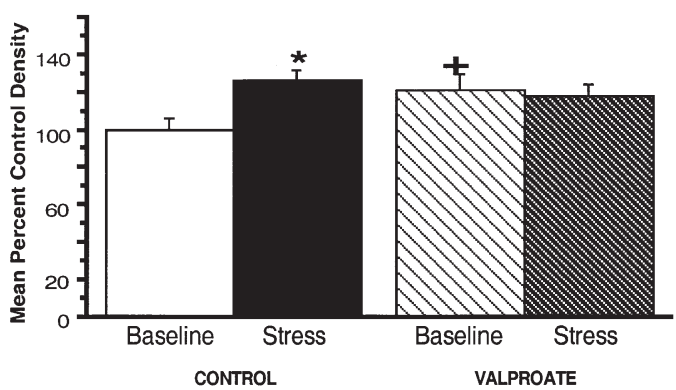

Figure 4. Effects of valproate treatment on the acute restraint stress-induced increase in TH mRNA expression in the locus coeruleus. (A) The TH mRNA response to restraint stress following acute vehicle or valproate treatment (baseline vehicle control: $n=15$, post-stress vehicle-treated: $n=$ 6, baseline valproate: $n=14$, post-stress valproate: $n=5$ ). (B) The TH mRNA response to restraint stress following chronic vehicle or valproate treatment (baseline vehicle control: $\mathrm{n}=11$, post-stress vehicle-treated: $\mathrm{n}=9$, baseline valproate: $\mathrm{n}=9$, post-stress valproate: $n=10)$. Mean integrated density is expressed as a percent of non-stressed,
VPA treatment in Experiment $2(n=5-7$ per group, Figure 4A). Acute restraint-stress induced a significant increase in TH mRNA expression in vehicle-treated rats, to $128 \%$ of unstressed controls $(p<.05)$. By contrast, restraint stress induced a modest nonsignificant increase in TH mRNA expression in acute VPA-treated animals, to $113 \%$ of unstressed VPA-treated rats (Figure $4 \mathrm{~A}$ ).

The increase in TH mRNA expression seen following chronic VPA-treatment in Experiment 1 was also replicated in Experiment 2. There was again a significant elevation in basal TH mRNA expression following chronic VPA treatment to $120 \%$ of vehicle-treated control levels $(\mathrm{n}=9-11$ per group, $p<.05$, Figure $4 \mathrm{~B})$. Chronic VPA treatment also had a significant attenuating effect on the acute restraint stress-induced elevation in TH mRNA expression in the LC. Whereas restraint stress induced a significant elevation in TH mRNA in vehicle-treated animals to $126 \%$ of unstressed controls, there was no change in TH mRNA expression in the LC following restraint stress in the chronic VPA-treated rats (Figure 4B).

In the acutely treated animals, there was, as expected, a significant effect of stress on plasma ACTH levels $\left(\mathrm{F}_{1,23}=80.24 ; p<.0001\right)$. Post-hoc analyses revealed that the increase in plasma ACTH seen in acute VPA-treated rats was less than that seen in the vehicletreated control group $(p<.05$, Figure 5A). Similarly, stress induced a significant increase in plasma ACTH in chronically-treated animals $\left(\mathrm{F}_{1,28}=36.62 ; p<.0001\right)$. As

vehicle-treated control. *: post-stress value significantly different from respective unstressed baseline $(p<.05)$. + : valproate-treated baseline significantly different from vehicletreated control baseline $(p<.05)$. 
in the acutely treated animals, post-hoc analyses revealed that the magnitude of the increase in plasma ACTH was significantly less in the chronic valproatetreated rats compared to their vehicle-treated counterparts $(p<.05$, Figure 5B).

\section{DISCUSSION}

In this study, the effects of acute and chronic treatment with the antimanic drug valproate on gene expression for components of the central noradrenergic system were determined. Both acute and chronic treatment with valproate induced increases in TH mRNA expression in the locus coeruleus, though the increase in the acutely treated animals was less robust than that in the chronically-treated animals. Moreover, the acute increase was less consistent, as it was not detected in the second experiment, suggesting that the modest increases seen after acute treatment may have represented the very earliest stages of drug-induced changes in TH mRNA expression in LC after valproate treatment. By contrast, the approximate $25 \%$ increase in $\mathrm{TH}$ mRNA expression seen in the LC of chronic VPAtreated animals was more robust and more consistent, suggesting that the VPA effects had stabilized by this

A

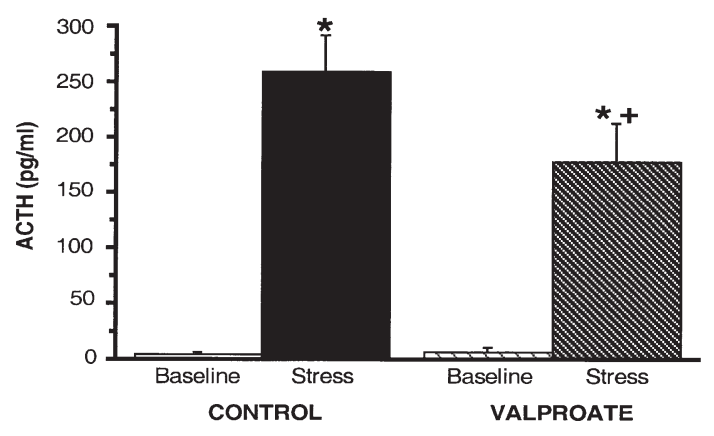

B

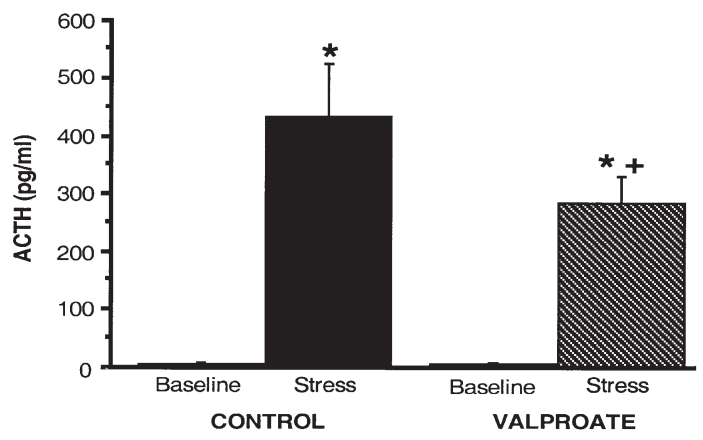

Figure 5. Effects of acute or chronic valproate treatment on the secretion of ACTH in response to restraint stress $(n=8$ per group). *: significantly different $(p<.05)$ from respective unstressed baseline. + : significantly different $(p<.05)$ from post-stress values in vehicle-treated control rats. later time point. Moreover, this effect appeared to be specific to TH, in that neither acute nor chronic VPA produced any changes in NET or $\alpha_{2 \mathrm{~A}}$ receptor mRNA expression in the same LC noradrenergic neurons. The observed increase in TH mRNA expression in the LC is consistent with a previous report of increased $\mathrm{TH}$ protein in the brain following chronic VPA treatment (Yuan et al. 1997). As the LC is the source of hippocampal NE, and TH is the rate-limiting enzyme in NE biosynthesis, our results are also consistent with a previous report that chronic administration of VPA increased hippocampal NE levels by $29 \%$ (Baf et al. 1994).

It is possible that VPA exerts a direct pharmacological effect on gene expression in the NE system via stimulation of cellular effector processes and subsequent activation of transcription factors. Two weeks of treatment with VPA increased the DNA binding activity of AP-1, but not CREB, in C6 glioma cells (Chen et al. 1997)., and VPA also stimulated transcriptional activity mediated by AP-1 (Chen et al. 1999). The promoter regions of the rat $\mathrm{TH}$ gene (Cambi et al. 1989), the mouse NET gene (Fritz et al. 1998) and the rat $\alpha_{2 \mathrm{~A}}$ gene (Yang et al. 1997) all contain AP-1 sites, though only the AP-1 site in the TH gene has been reported to functionally activate gene transcription (Icard-Liepkalns et al. 1992). Thus, it is possible that the AP-1 site may be involved in the elevation of TH mRNA expression seen with valproate treatment, but the specificity of the response may require the involvement of other factors that do not regulate the NET or $\alpha_{2 \mathrm{~A}}$ genes to the same extent. For instance, chronic VPA treatment has been shown to decrease levels of PKC alpha and epsilon (Chen et al. 1994). This has been suggested to be a result of chronic PKC activation (Manji and Lenox 1994), and activation of PKC by administration of phorbol ester activates TH gene transcription (Vyas et al. 1990). Chronic VPA treatment has also been shown to decrease levels of myristoylated alanine-rich C kinase substrate (MARCKS) (Lenox et al. 1996), providing further evidence of an interaction of VPA with PKC. Similar effects on PKC activity and MARCKS have been observed following administration of lithium, another effective antimanic agent (Manji et al. 1996; Manji and Lenox 1994).

Valproate-induced increases in TH mRNA expression in the locus coeruleus may also be attributable in part to an indirect effect exerted via changes in GABAergic neurotransmission in the brain. The antiepileptic effects of VPA are thought to be mediated through inhibition of GABA transaminase, increasing GABA extracellularly and thus suppressing seizure activity (Loscher 1993). VPA has also been demonstrated to potentiate the hyperpolarizing effects of GABA on neuronal activity of the LC (Olpe et al. 1988). By enhancing the effects of GABA, VPA may therefore inhibit LC neuronal activity and decrease NE release (Os- 
manovic and Shefner 1990). However, TH expression has been shown to increase with depolarization of A6 neurons in vitro (Dreyfus et al. 1986). It has further been demonstrated in vivo that stimuli which elevate $\mathrm{TH}$ mRNA expression in the LC tend to elevate the activity of LC neurons (Melia et al. 1992). Thus, it seems unlikely that the elevation in TH gene expression induced by VPA was a direct result of enhanced GABAergic inhibition of LC neuronal activity. Rather, it would seem more likely to be the result of indirect compensatory or reactive homeostatic processes mediated by long-loop feedback circuits conveying information about changes in effective NE neurotransmission in post-synaptic target regions of the LC.

In addition to an elevation in basal TH message expression, chronic treatment of rats with VPA attenuated the increase in TH message expression seen in response to acute restraint stress, perhaps reflective of a VPAinduced decrease in stress-reactivity of the noradrenergic system. Because chronic VPA treatment itself induced an increase in basal expression of TH mRNA, it is possible that any subsequent stress-induced increase could have been more difficult to detect. However, it is unlikely that the lack of a stress-induced increase in $\mathrm{TH}$ mRNA expression was due to a ceiling effect, because the magnitude of the increase in basal expression produced by chronic VPA does not appear to be near maximal. Reserpine administration has been reported to induce up to several-fold increases in TH mRNA expression (McMahon et al. 1992). When reserpine (10 $\mathrm{mg} / \mathrm{kg}$, i.p.) was administered to a small number of animals that were processed together with the subjects in the current study, we observed a $55 \%$ increase in $\mathrm{TH}$ mRNA in the LC measured 48 hours after reserpine treatment (unpublished observation). As compared to the $25 \%$ increase in basal expression induced by chronic VPA, this would suggest that there was still some capacity for stress to increase $\mathrm{TH}$ mRNA expression in the LC after chronic VPA treatment. Thus it appears that chronic VPA attenuated the acute stress-reactivity of the LC, at least the component of reactivity represented by stress-induced changes in TH gene expression.

In addition to attenuating the increase in TH mRNA following stress, valproate also attenuated acute restraint stress-induced increases in plasma ACTH levels, with no apparent effect on pre-stress basal ACTH. Similar effects of VPA on ACTH or corticosterone levels have been reported in rats using ether stress (Jones et al. 1984) or restraint stress (Petraglia et al. 1986). Further, VPA reduced the elevated plasma ACTH levels seen in humans with Nelson's or Cushing's disease without altering ACTH levels in normal human volunteers (Elias et al. 1981; Jones et al. 1984). However, basal hypothalamic CRF and plasma corticosterone, but not ACTH, have been reported to be elevated in valproate-treated rats (Jones et al. 1984). These investigators further showed that the response to CRF in the anterior pituitary was reduced, indicating an alteration in CRF receptor expression and/or activity. These findings suggest that valproate can perhaps selectively counteract dysregulation of the HPA axis, often associated with affective disorders, without affecting basal activity.

Central NE is hypothesized to facilitate stressinduced HPA activation through stimulation of $\alpha_{1}$ adrenergic receptors (Gibson et al. 1986; Kiss and Aguilera 1992; Plotsky 1987; Szafarczyk et al. 1987). Therefore, a reduction in central noradrenergic reactivity induced by VPA may contribute to the attenuation of acute stress-induced HPA activation seen following VPA treatment. Whereas it is unlikely, for the reasons discussed above, that VPA influenced TH mRNA expression in the LC by modulating GABA neurotransmission, it is possible that this mechanism does play a role in attenuating stress-induced ACTH secretion.

Current hypotheses suggest that dysregulation of NE neurotransmission may occur in qualitatively opposite directions in certain forms of depressive illness as compared to bipolar disorder or mania (Schatzberg and Schildkraut 1995). Consistent with this, the effects exerted by antidepressant drugs on $\mathrm{TH}$ gene expression in the LC appear to be opposite in nature to the effects of VPA observed in the present study. In contrast to the increase observed following VPA treatment, we and others have shown a decrease in TH mRNA expression following chronic antidepressant treatment (Brady et al. 1991; Morilak et al. 1998; Nestler et al. 1990). There is also evidence for opposing effects of antidepressants and VPA on second messengers in the NE neurotransmitter system. In contrast to the increase in PKC activity elicited by VPA, chronic treatment with desipramine caused a decrease in PKC activity in the particulate fractions of the cortex and hippocampus (Mann et al. 1995). These observations are consistent with theories suggesting that monopolar depression and bipolar affective disorder may involve underlying mechanisms that are qualitatively opposite in nature.

The dysregulation of the HPA axis that is often associated with a variety of affective disorders may also reflect abnormalities in specific modulatory neurotransmitter systems, such as the noradrenergic system, that are involved in both the regulation of mood and in the response to stress. Drugs that are effective in treating such disorders, including novel antimanics such as valproate, may induce regulatory changes in these systems that result in the stabilization and normalization of both mood and stress reactivity. Lithium, another antimanic drug, has also been shown to attenuate stress-mediated effects in rats, although the neuroendocrinological effects of lithium with regard to the HPA axis have not been well-examined (Kofman et al. 1995). The results of the present study and others (Jones et al. 1984; Delbende et al. 1991) would suggest that both antimanics and anti- 
depressants can attenuate stress-induced increases in HPA activity. Thus, whereas each type of drug can induce different, even opposite regulatory changes in the neurotransmitter systems that modulate mood and stress reactivity, an indirect result in each case may be the stabilization of systems such as the HPA axis that may be dysregulated secondarily, and in a similar fashion, in these very different mood disorders.

\section{ACKNOWLEDGMENTS}

This work was supported by research grants from The Whitehall Foundation and NIMH (MH 53851). We thank Ms. Gabriela Helesic for expert technical assistance.

\section{REFERENCES}

Aston-Jones G, Chiang C, Alexinsky T (1991): Discharge of noradrenergic locus coeruleus neurons in behaving rats and monkeys suggests a role in vigilance. Prog Brain Res 88: 501-520

Baf MH, Subhash MN, Lakshmana KM, Rao BS (1994): Sodium valproate induced alterations in monoamine levels in different regions of the rat brain. Neurochem Int 24: $67-72$

Bowden CL, Brugger AM, Swann AC, Calabrese JR, Janicak PG, Petty F, Dilsaver SC, Davis JM, Rush AJ, Small JG, Garza-Trevino ES, Risch SC, Goodnick PJ, Morris DD (1994): Efficacy of divalproex vs lithium and placebo in the treatment of mania. JAMA 271: 918-924

Brady LS, Whitfield HJ, Fox RJ, Gold PW, Herkenham M (1991): Long-term antidepressant administration alters corticotropin-releasing hormone, tyrosine hydroxylase, and mineralocorticoid receptor gene expression in rat brain. J Clin Invest 87: 831-837

Cambi F, Fung B, Chikaraishi D (1989): 5' flanking DNA sequences direct cell-specific expression of rat tyrosine hydroxylase. J Neurochem 53: 1656-1659

Charney DS, Woods SW, Nagy LM, Southwick SM, Krystal JH, Heninger GR (1990): Noradrenergic function in panic disorder. J Clin Psychiat 51 (Suppl. A): 5-11

Chen G, Manji HK, Hawver DB, Wright CB, Potter WZ (1994): Chronic sodium valproate selectively decreases protein kinase $C \alpha$ and $\epsilon$ in vitro. J Neurochem 63: 23612364

Chen G, Yuan P, Hawver DB, Potter WZ, Manji HK (1997): Increase in AP-1 transcription factor DNA binding activity by valproic acid. Neuropsychopharmacology 16: 238-245

Chen G, Yuan P-X, Jiang Y-M, Huang L-D, Manji HK (1999): Valproate robustly enhances AP-1 mediated gene expression. Mol Brain Res 64: 52-58

Delbende C, Contesse V, Mocaer E, Kamoun A, Vaudry H (1991): The novel antidepressant, tianeptine, reduces stress-evoked stimulation of the hypothalamo-pituitary-adrenal axis. Eur. J Pharmacol 202: 391-396
Dreyfus CF, Friedman WJ, Markey KA, Black IB (1986): Depolarizing stimuli increase tyrosine hydroxylase in the mouse locus coeruleus in culture. Brain Res 379: 216-222

Elias AN, Gwinup G, Valenta LJ (1981): Effects of valproic acid, naloxone and hydrocortisone in Nelson's syndrome and Cushing's disease. Clin Endocrinol 15: 151-154

Foote SL, Bloom FE, Aston-Jones G (1983): Nucleus locus coeruleus: New evidence of anatomical and physiological specificity. Physiol Rev 63: 844-914

Fritz JD, Jayanthi LD, Thoreson MA, Blakely RD (1998): Cloning and chromosomal mapping of the murine norepinephrine transporter. J Neurochem 70: 2241-2251

Gibson A, Hart SL, Patel S (1986): Effects of 6-hydroxydopamine-induced lesions of the paraventricular nucleus, and of prazosin, on the corticosterone response to restraint in rats. Neuropharmacol 25: 257-260

Icard-Liepkalns C, Faucon Biguet N, Vyas S, Robert JJ, Sassone-Corsi P, Mallet J (1992): AP-1 complex and c-fos transcription are involved in TPA provoked and transsynaptic inductions of the tyrosine hydroxylase gene: insights into long-term regulatory mechanisms. J Neurosci Res 32: 290-298

Jones MT, Gillham B, Altaher ARH, Nicholson SA, Campbell EA, Watts SM, Thody A (1984): Clinical and experimental studies on the role of GABA in the regulation of ACTH secretion: A review. Psychoneuroendocrinol 9: 107-123

Kiss A, Aguilera G (1992): Participation of $\alpha_{1}$-adrenergic receptors in the secretion of hypothalamic corticotropinreleasing hormone during stress. Neuroendocrinol 56: 153-160

Kofman O, Levin U, Alpert C (1995): Lithium attenuates hypokinesia induced by immobilization stress in rats. Prog Neuro-Psychopharmacol Biol Psychiat 19: 10811090

Lenox RH, McNamara RK, Watterson JM, Watson DG (1996): Myristoylated alanine-rich C kinase substrate (MARCKS): a molecular target for the therapeutic action of mood stabilizers in the brain. J Clin Psychiatry 57 (suppl 13): 23-31

Loscher W (1993): Effects of the antiepileptic drug valproate on metabolism and function of inhibitory and excitatory amino acids in the brain. Neurochem Res 18: 485-502

Loscher W, Fisher JE, Nau H, Honack D (1989): Valproic acid in amygdala-kindled rats: Alterations in anticonvulsant efficacy, adverse effects and drug and metabolite levels in various brain regions during chronic treatment. J Pharmacol Exper Therap 250: 1067-1078

Manji HK, Chen G, Hsiao JK, Risby ED, Masana MI, Potter WZ (1996): Regulation of signal transduction pathways by mood-stabilizing agents: Implications for the delayed onset of therapeutic efficacy. J Clin Psychiat 57 (Suppl.13): $34-46$

Manji HK, Lenox RH (1994): Long-term action of lithium: a role for transcriptional and posttranscriptional factors regulated by protein kinase C. Synapse 16: 11-28

Mann CD, Vu TB, Hrdina PD (1995): Protein kinase C in rat brain cortex and hippocampus: effect of repeated administration of fluoxetine and desipramine. Br J Pharmacol 115: 595-600 
McMahon A, Kvetnansky R, Fukuhara K, Weise VK, Kopin IJ, Sabban EL (1992): Regulation of tyrosine hydroxylase and dopamine $\beta$-hydroxylase mRNA levels in rat adrenals by a single and repeated immobilization stress. J Neurochem 58: 2124-2130

Melia KR, Rasmussen K, Terwilliger RZ, Haycock JW, Nestler EJ, Duman RS (1992): Coordinate regulation of the cyclic AMP system with firing rate and expression of tyrosine hydroxylase in the rat locus coeruleus: Effect of chronic stress and drug treatments. J Neurochem 58: 494-502

Moore RY, Bloom FE (1979): Central catecholamine neuron system: Anatomy and physiology of the norepinephrine and epinephrine systems. Ann Rev Neurosci 2: 113-168

Morilak DA, Blincoe S, Sands SA (1998): Changes in gene expression in the rat locus coeruleus following acute or chronic desipramine or valproate. Soc Neurosci Abs 24: 1988

Nestler EJ, McMahon A, Sabban EL, Tallman JF, Duman RS (1990): Chronic antidepressant administration decreases the expression of tyrosine hydroxylase in the rat locus coeruleus. Proc Natl Acad Sci USA 87: 7522-7526

Olpe HR, Steinmann MW, Pozza MF, Brugger F, Schmutz M (1988): Valproate enhances GABA-A mediated inhibition of locus coeruleus neurones in vitro. N-S Arch Pharmacol 338: 655-657

Osmanovic SS, Shefner SA (1990): $\gamma$-aminobutyric acid responses in rat locus coeruleus neurons in vitro: a current-clamp and voltage-clamp study. J Physiol 421: 151-170

Paxinos G, Watson C (1986) The Rat Brain in Stereotaxic Coordinates, 2nd Edition. Academic Press, Academic Press

Petraglia F, Bakalakis S, Facchinetti F, Volpe A, Muller EE, Genazzani AR (1986): Effects of sodium valproate and diazepam on beta-endorphin, beta-lipotropin and cortisol secretion induced by hypoglycemic stress in humans. Neuroendocrinol 44: 320-325

Plotsky PM (1987): Facilitation of immunoreactive corti- cotropin-releasing factor secretion into the hypophysialportal circulation after activation of catecholaminergic pathways or central norepinephrine injection. Endocrinol 121: 924-930

Puumala T, Riekkinen P, Sirvio J (1997): Modulation of vigilance and behavioral activation by alpha- 1 adrenoceptors in the rat. Pharm Biochem Behav 56: 705-712

Schatzberg AF, Schildkraut JJ (1995): Recent studies on norepinephrine systems in mood disorders. In Bloom FE, Kupfer DJ, (eds), Psychopharmacology: The Fourth Generation of Progress. Raven Press, Ltd., New York, pp 911-920

Schildkraut JJ (1965): The catecholamine hypothesis of affective disorders: a review of supporting evidence. Am J Psychiatry 122: 509-522

Siegel JM, Rogawski MA (1988): A function for REM sleep: regulation of noradrenergic receptor sensitivity. Brain Res Revs 13: 213-233

Szafarczyk A, Malaval F, Laurent A, Gibaud R, Assenmacher I (1987): Further evidence for a central stimulatory action of catecholamines on adrenocorticotropin release in the rat. Endocrinol 121: 883-892

Van den Berg RJ, Kok P, Voskuyl RA (1993): Valproate and sodium currents in cultured hippocampal neurons. Exp Brain Res 93: 279-287

Vyas S, Faucon Biguet N, Mallet J (1990): Transcriptional and post-transcriptional regulation of tyrosine hydroxylase gene by protein kinase C. EMBO J 9: 3707-3712

Yang N, Eckhart AD, Xin X, Faber JE (1997): CRE-like response element regulates expression of rat $\alpha_{2 D}$-adrenergic receptor gene in vascular smooth muscle. Am J Physiol 273: H85-H95

Yuan PX, Chen G, Granneman JG, Manji HK (1997): Increase in the expression of AP-1 regulated genes in brain by the mood stabilizing agents lithium and valproic acid. Soc Neurosci Abs 27: 2045 